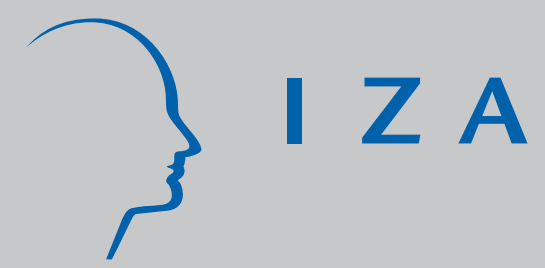

IZA DP No. 7586

Peer Groups, Employment Status and Mental Well-being among Older Adults in Ireland

Eibhlin Hudson

Alan Barrett

August 2013

Forschungsinstitut zur Zukunft der Arbeit Institute for the Study of Labor 


\title{
Peer Groups, Employment Status and Mental Well-being among Older Adults in Ireland
}

\author{
Eibhlin Hudson \\ TILDA, Trinity College Dublin \\ Alan Barrett \\ Economic and Social Research Institute, \\ Trinity College Dublin and IZA \\ Discussion Paper No. 7586 \\ August 2013 \\ IZA \\ P.O. Box 7240 \\ 53072 Bonn \\ Germany \\ Phone: +49-228-3894-0 \\ Fax: +49-228-3894-180 \\ E-mail: iza@iza.org
}

\begin{abstract}
Any opinions expressed here are those of the author(s) and not those of IZA. Research published in this series may include views on policy, but the institute itself takes no institutional policy positions. The IZA research network is committed to the IZA Guiding Principles of Research Integrity.

The Institute for the Study of Labor (IZA) in Bonn is a local and virtual international research center and a place of communication between science, politics and business. IZA is an independent nonprofit organization supported by Deutsche Post Foundation. The center is associated with the University of Bonn and offers a stimulating research environment through its international network, workshops and conferences, data service, project support, research visits and doctoral program. IZA engages in (i) original and internationally competitive research in all fields of labor economics, (ii) development of policy concepts, and (iii) dissemination of research results and concepts to the interested public.
\end{abstract}

IZA Discussion Papers often represent preliminary work and are circulated to encourage discussion. Citation of such a paper should account for its provisional character. A revised version may be available directly from the author. 


\title{
ABSTRACT \\ Peer Groups, Employment Status and Mental Well-being among Older Adults in Ireland
}

\begin{abstract}
Research has shown that employment status, such as being unemployed or retired, can be related to well-being. In addition, the direction and size of these relationships can be influenced by the employment status of one's peer group. For example, it has been shown that the well-being of the unemployed tends to be higher for those living in highunemployment areas compared to the unemployed living in low-unemployment areas. In this paper, we explore whether such employment peer effects impact upon the well-being of older workers. This is an important issue in the context of promoting longer working lives. If the well-being of older people in employment is lowered by low employment levels in their peer group, then sustaining high employment among older workers will be more difficult. We use data from the Irish Longitudinal Study on Ageing (TILDA) which is a nationally representative sample of people aged fifty and over and living in Ireland, collected between 2009 and 2011. Employment peer effects are proxied using the peer group non-employment rate where a peer is defined as someone in the same age-group and region and of the same gender. We find that for the employed, an increase in peer non-employment is associated with an increase in reported depressive symptoms, whereas for those not employed such an increase is associated with a decrease in reported depressive symptoms. However, these findings hold mainly for men.
\end{abstract}

JEL Classification: I10, J26, C21

Keywords: peer groups, well-being, older adults

Corresponding author:

Eibhlin Hudson

The Irish Longitudinal Study of Ageing (TILDA)

Lincoln Gate

Trinity College

Dublin 2

Republic of Ireland

E-mail: eibhlin.hudson@tcd.ie 


\section{Introduction}

The literature on the relationship between employment status (mainly unemployment) and mental well-being has recently sought to incorporate peer group effects. While earlier studies sought to explore how unemployment and retirement impacted upon people in an individualistic context, more recent work has explored if these relationships are influenced by the employment status of one's peer group. This line of research has been partly motivated by Akerlof's (1980) theory of social custom which describes "norms" as the beliefs held by society or relevant others. His model describes how a code can emerge which defines how people should behave - if people do not follow this code they incur a loss in reputation. For example, there may be a stigma attached to not being employed. More generally, peer effects can describe how the circumstances of others, beyond family and friends, impact on individuals.

Evidence of such peer group effects has been found in the UK in relation to unemployment. Using data from seven waves (1991-1997) of the British Household Panel Survey (BHPS) it was found that the unemployed living in areas of high unemployment were found to have higher levels of subjective well-being (as measured by the 12-item General Health Questionnaire) than their counterparts in areas with lower un-employment levels. Conversely it was found that the employed living in areas of high unemployment have lower levels of subjective well-being than their counterparts in areas with lower unemployment levels (Clark, 2003). However, this effect was mainly found for men. In addition the unemployed who were hurt less by unemployment were less likely to seek employment and, one wave into the future, were more likely to remain unemployed. 
Evidence of peer group effects was found in South Africa, using cross-sectional data from the 1993 SALDRU93 survey, where well-being was measured using Perceived Quality of Life (PQOL) at the household-level (Powdthavee, 2006). (The Perceived Quality of Life (PQOL) question was: Taking everything into account, how satisfied is this household with the way it lives these days?) Further evidence of a peer effect was found in Germany using data from 23 waves (1984-2006) of the German Socio-Economic Panel (GSOEP) which replicates the UK study described above where well-being is measured using life satisfaction (Clark, 2008). As with the UK study the effect of the peer effect was strongest for men.

These findings give rise to the questions of (a) whether the employment of others matters for the mental well-being older people and (b) whether any such relationship is altered by the employment status of the individual in question. Social norms and broader peer effects may be particularly relevant for older people. Labour force withdrawal, voluntary or otherwise, becomes more commonplace as one gets older. With such changes taking place, older people may give increased attention to the behaviour and employment circumstances of other people to help inform their decisions or to assess their circumstances. If older people see increased numbers of peers who are not employed because of retirement, this may generate a sense of resentment for those who remain at work. Similarly, older people who find themselves out of employment, possibly through a forced exit related to health, may feel resentment if most of their peers are still at work. The relationship between employment and mental health among older workers is of particular interest to policymakers who are increasingly seeking to bring retirement ages more in line with increases in longevity (Van Solinge and Henkens, 2010).

In this study we develop this literature by focusing on older people in Ireland. Using recently collected data from the first wave of the Irish Longitudinal Study on 
Ageing (known as TILDA) which is a representative panel of people aged 50 and over in Ireland we find that for those who are employed an increase in the proportion of those who are not employed is associated with an increase in reported depressive symptoms. Conversely, for those who are not employed an increase in the proportion of those who are also not employed is associated with a decrease in reported depressive symptoms. However, as with the studies above, these findings hold mainly for men.

Our findings are of interest not only because they provide insight into the relationship between mental health and employment for older people and add further evidence on the existence of peer effects and interactions, but because they broaden our understanding of the possible influences on retirement decisions.

One prediction of Akerlof's theory is that if a code is too costly to follow, in terms of lost utility, then it will not be followed and the code will diminish and disappear. Clark's (2003) finding that those who were hurt less by unemployment were less likely to seek employment supports this prediction. He suggests that this underlines the need to prevent a new social norm of higher unemployment following a negative employment shock as the utility benefit from gaining employment is lower than if unemployment was not so common. For older people a comparable recommendation could be made so as to prevent a social norm of early retirement becoming established or to promote a new norm of working to an older age.

The remainder of the paper is structured as follows: Section 2 describes the data and methodology employed; Section 3 presents and discusses the main empirical findings and Section 4 concludes this study. 


\section{Methodology and Data}

This study uses data from The Irish Longitudinal Study on Ageing (TILDA) which is a nationally representative sample of people aged 50 and over in Ireland (and their spouses of any age). To create the TILDA sample, all residential postal addresses in Ireland were assigned to one of 3,155 geographic clusters. A sample of 640 of these clusters was selected. Clusters were selected with a probability proportional to the number of individuals aged 50 and over in each cluster (Savva 2011).

This dataset contains a rich set of variables on the health and socio-economic circumstances of older people. The first wave was collected from late 2009 until early 2011. The overall response rate among randomly chosen eligible households was 62 percent $(n=8,504)$. The data were weighted to account for differential nonresponse using census data provided by the Irish Central Statistics Office. In this study we focus on those who are of traditional working age, that is, aged 50 up to 65 years old for whom we have complete information. This results in a sample size of 4,089 . This excludes those who have never done paid work.

\subsection{Mental Well-being}

The mental well-being outcome we focus on in this study is the Center for Epidemiological Studies Depression Scale (CESD) (Radlo, 1977) which is designed to measure depressive symptoms in the general population. Respondents are asked questions relating to 20 major symptoms of depression, such as depressive mood, feelings of guilt, loss of appetite and sleep disturbance. Respondents are asked to indicate how often experienced each symptom in the past week on a four-point scale: rarely/none of the time, some of the time, most of the time, or all of the time. A value of $0,1,2$ or 3 is assigned to a response depending on whether the item is worded positively or negatively. These values are then 
summed to give a variable which ranges from 0 to 60 . A score between 8 and 16 suggests sub-threshold depression and a score of 16 or above suggests that the respondent may be clinically depressed. The measure has been shown to be internally consistency with adequate test-retest repeatability. In addition, the measure has been shown to be is well correlated with other self-reported measures and with clinical ratings of depression (Radlo, 1977). As shown in Table 1, the mean CESD score and the proportion of people with High Depression levels (CESD score greater than 16) are higher among those who are not employed.

Table 1 approximately here.

\subsection{Employment and Employment Peer Effects}

Defining the employment status of older people (who are not in paid employment) may present a number of issues. For example, a 60 year old man who has been made redundant may classify himself as retired rather than unemployed as it may be more socially acceptable. Older people who take courses may be taking the course for pleasure during their retirement, or to enhance their prospects for job market re-entry. Rather than risk making incorrect assumptions regarding these issues we use a broad employment definition: respondents are categorised as either employed (E) or not employed (NE). These issues have been faced in other studies and similar approaches have been taken. For example, (Butterworth et al., 2006) uses two broad employment categories for older people: retired and not retired, where they use absence from the labour force among older people (45-74) as a proxy for retirement and only the unemployed who were actively seeking employment were classified as being in the labour force. Aside from the treatment of the unemployed this definition is identical to ours and thus the "not employed" category could be considered a retirement proxy (Results replicated using Butterworth's categorisation yields similar 
results.). By using broad employment categories we avoid situations where the cell sizes become too small.

Akerlof (1980) defined norms as the beliefs held by society or relevant others. How do we decide who is relevant? Research suggests that people tend to compare themselves to those in the same region (Knight et al., 2009, Clark and Senik, 2010). In addition, those of the same gender and age-group (five-year age bands are constructed: $50-54,55-59,60-64)$ are likely to be most relevant. Therefore we define reference groups based on region $r$, gender $g$ and age-group a. For most respondents county is used to define their region, with 26 counties in the Republic of Ireland. However, region is further broken down for those living in Dublin (Dublin North, Dublin City and Dublin South) and for those in counties containing a city. This reference group definition yields almost 200 groups.

Using this Region-Gender-Age group reference group definition we construct our peer employment variable (Prop. NE) as the proportion of people in the same reference group as respondent $i$ who are not employed (NE).

$$
\text { Prop. } N E_{\text {irga }}=\frac{\text { No. in Reference Group } N E_{- \text {irga }}}{\text { No. in Reference Group } p_{- \text {irga }}}
$$

\subsection{Empirical Model}

Equation 2 describes our modelling approach. Following Clark (2003) we model mental well-being, in this case depression (CESD), using individual employment status $\left(N E_{i}\right)$ and the non-employment rate in the respondent's reference group (Prop. $N E_{i}$ ). We also include an interaction term between own employment status and the reference group non-employment rate $\left(N E_{i}{ }^{*}\right.$ Prop. $\left.N E_{i}\right)$ and this is the critical variable in our analysis because it allows us to assess how the impact of any peer effect varies according to the employment status of the individual. Our 
measure of depression, CESD, ranges from 0 to 60 and so one could use a standard regression model for estimation. Alternatively, we could use the categorized version of this variable as described above and use an ordered probit model. Both estimation methods are used and produce consistent results.

$$
C E S D_{i}=\beta_{1} N E_{i}+\beta_{2} \operatorname{Prop} . N E_{i}+\beta_{3}\left(N E_{i} * \operatorname{Prop} . N E_{i}\right)+\beta_{4} X+\epsilon_{i}
$$

We also include a number of controls denoted by $X_{i}$ which include age, gender, marital status, whether the respondent has children and their education (primary, secondary or tertiary) and income (categories). We control for self-reported health status, the presence of a doctor diagnosed chronic condition and whether the respondent has any difficulties with Activities of Daily Living (ADL) (for example, walking 100 meters).

We also include a measure of how social integration using a modified version of the Berkman-Syme Social Network Index. This measure considers the number of close relationships one has with family and friends and whether they volunteer or they participate in social or religious groups. A value of one is added to a respondents score if the individual has at least two children, other relatives or friends he/she feels close to and zero otherwise. A value of one is added to a respondents score if the individual participates in any groups and zero otherwise. A value of one is added to a respondents score if the individual attends religious services at least once per month and zero otherwise. This results in a score ranging from 0 to three. We consider those who score 2 or 3 to be socially integrated. Descriptive statistics on the explanatory variables are provided in Table 2.

Table 2 about here 


\section{Results}

In order to get an initial indication of an interaction between the employment status of the individual and the employment status of the peer group, we construct a variable to denote whether the proportion of people in a respondent's reference group not employed is above or equal to 0.5 (low employment area) or below 0.5 (high employment area). We then examined the mean CESD score for those employed and not employed in these areas. From Figure 1 we see that those not employed in areas of low employment have lower reported depressive symptoms than those not employed in areas of high employment. For the employed, the figure does not reveal much of a difference between the two groups. However, the employed living in areas of low employment report more depressive symptoms than those in areas of high employment.

Figure 1 approximately here.

The baseline regression results reported in Table 3 suggest that those in the labour force are less likely to report mental health problems than those not in the labour force. We also observe a common finding in the literature which is that as people get older they are less likely to report mental health problems. Men also tend to report fewer mental health problems than women. Socio-economic status, as measured by income and education, is associated with lower depression levels. However this is mainly the case for women. Those who have never been married, divorced or separated or widowed report high depression levels than those who are married. There does not appear to be any statistically significant difference in depression levels among those with and without children. Those living in a rural area report fewer depression levels than those living in Dublin (though this appears to mainly hold for women). Those who report growing up poor report more depressive symptoms than those who do not. Those with good 
or excellent self-reported health report fewer depressive symptoms than those who report fair or poor health. However these two health variables should be interpreted with caution as it is likely to be endogenous. No statistically significant difference between those who did and did not report a doctor-diagnosed disease was observed. Those who report having an ADL impairment or limitation report more depressive symptoms than those without any ADL impairments. Those who are socially integrated report fewer depressive symptoms than those are not socially integrated. Finally, those who are not employed report more depressive symptoms that those who are employed.

Table 3 approximately here.

We then examine the effect of peer group employment status by including a variable denoting the proportion of those in the same region (county) and of the same gender and age-group who are not employed. It is also possible that the effect of reference group employment may depend of the respondent's own employment status - for this reason, we include the interaction term discussed above. Those in the labour market may enjoy knowing others are also in the labour market. Those not in the labour market may feel stigmatised if others are in the labour market. So depending on your own status how you view regional labour force participation rates may vary.

The results of this model are contained in Table 4. These models are estimated using the full set of controls shown in Table 3 but are removed here for ease of illustration but are available upon request. Not surprisingly we find that not being employed is associated with an increase in depressive symptoms. We also find that higher rates of non-employment in the peer group are associated with an increase in depressive symptoms. However, we also find that there is a negative association between the proportion of others not employed and depression for 
those who are not employed. Figure 2 illustrates this finding. The downward sloping line (unbroken) shows the decreasing depression levels among those not employed. The upward sloping line (broken) shows the associated increasing depression levels among those who are employed. This figure also illustrates that when the non-employment rate is very high there is little difference in depression levels between these two groups. These results are broadly consistent with those found in other studies (Clark, 2003; Clark et al., 2008; Powdthavee, 2006).

Figure 2 approximately here.

When disaggregated by gender we do not find evidence of a peer employment effect for women. The coefficients on reference group employment are smaller than those found for men and are not statistically significant. This finding is consistent with studies in other countries.

Table 4 approximately here.

We also model our results using an ordered probit model where the outcome is: no depressive symptoms, sub-threshold depression and clinically significant depressive symptoms. The results of the ordered probit analysis (shown in Table 5) are broadly in line with those shown estimated using OLS.

As a robustness test we estimate both OLS and ordered probit models where groups with less than 10 people are eliminated and find that the results are very similar.

Table 5 approximately here.

Categorizing the employment of older people can be complex with many possible categories (employed full-time, employed part-time, retired, semi-retired, retired but working full-time, sick, looking after or caring for a family member, in education or training, unemployed). As a result we have defined two broad 
categories: employed and not employed. This definition should reduce measurement error compared to a wider range of categories and will permit comparability with other countries. However, the drawback of this is that there is likely to be different effects depending on why a given individual is not in employment. Aside from possible measurement error, measuring employment norms for such categories will not only become tedious but are likely to be inaccurate due to small cell sizes.

\section{Conclusion}

Research by Clark (2003) and others has shown that the employment status of one's peers can have an impact on mental well-being and that this impact can vary according to the employment status of the individual in question. In the context of unemployment, Clark's results showed how the negative impact of unemployment was diminished if an individual was surrounded by other unemployed people. In this way, a damaging dynamic could develop whereby efforts to escape from unemployment could fall as the rate of unemployment climbs in a local area.

In this paper, we have shown how depression appears to rise for employed older people if the extent of non-employment rises in their peer group. There are a number of possible causes. If employed older people perceive that their nonworking peers have retired and are now enjoying more leisure, this may lead to resentment for those who believe that they cannot afford to retire. Whether this is the explanation or not, the result is important in the context of promoting longer working lives. If a sufficiently large number of older people continue to exit the labour force, our results suggest that the mental well-being of those who remain at work will decline, thereby increasing the likelihood that they too will 
exit. In this way, a dynamic is generated which works against a stated policy aim of many governments, i.e. prolonging working lives.

This paper represents an early attempt to explore the notion of peer effects in the employment sphere for older people. The results suggest that the line of research should be developed further. 


\section{References}

George A. Akerlof. A Theory of Social Custom, of which Unemployment may be one Consequence. The Quarterly Journal of Economics, 94(4):749-775, 1980.

Peter Butterworth, Sarah C Gill, Bryan Rodgers, Kaarin J Anstey, Elena Villamil, and David Melzer. Retirement and mental health: analysis of the Australian national survey of mental health and well-being. Social Science \& Medicine, 2006.

Andrew E. Clark. Unemployment as a Social Norm: Psychological Evidence from Panel Data. Journal of Labor Economics, 21(2):323-351, 2003.

Andrew E. Clark, Andreas Knabe and Steffen Ratzel. Unemployment as a Social Norm in Germany. SOEP Paper. 132, 2008.

Andrew E. Clark and Claudia Senik. Who Compares to Whom? The Anatomy of Income Comparisons in Europe. The Economic Journal, 120(544):573-594, 2010.

Andrew E. Clark, Paul Frijters, and Michael A. Shields. Relative Income, Happiness, and Utility: An Explanation for the Easterlin Paradox and Other Puzzles. Journal of Economic Literature, 46(1):95-144, 2008.

John Knight, Lina Song, and Ramani Gunatilaka. Subjective Well-being and its Determinants in Rural China. China Economic Review, 20:635-649, 2009.

David Melzer, Julian Buxton, and Elena Villamil. Decline in common mental disorder prevalence in men during the sixth decade of life. Social Psychiatry and Psychiatric Epidemiology, 39(1):33-38, 2004.

Nattavudh Powdthavee. Are there Geographical Variations in the Psychological Cost of Unemployment in South Africa? Social Indicators Research, 80(3):629-652, 2006. 
Hanna Van Solinge and Kene Henkens. Living longer, working longer? The Impact

of Subjective Life Expectancy on Retirement Intentions and Behaviour. The European Journal of Public Health, 20(1):47-51, 2010. 
Figures and Tables

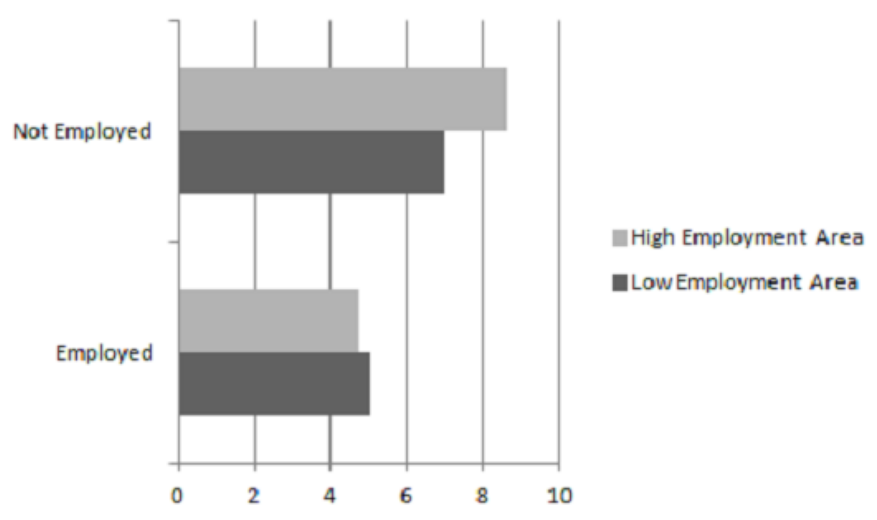

Fig. 1 Mean Depression Level (CESD Score) by Own Employment Status and Employment Status in Area

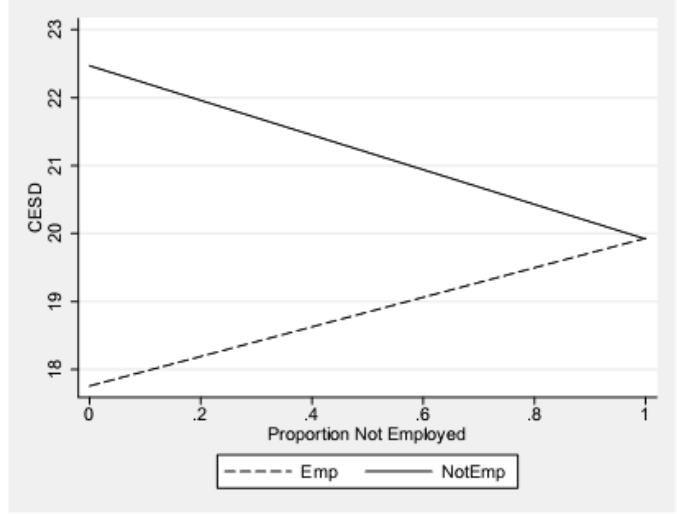

Fig. 2 Does the Effect of Others depend on Employment Status?

Table 1 Depression by Employment Status

\begin{tabular}{lrr}
\hline Employed & Mean CESD & Proportion with High Depression \\
\hline Not employed & 7.56 & 0.16 \\
Employed & 4.77 & 0.06 \\
Total & 5.90 & 0.10 \\
\hline Sample size & 4,098 & \\
\hline
\end{tabular}




\begin{tabular}{|c|c|c|c|c|}
\hline & \multicolumn{2}{|c|}{ Gender } & \multirow{3}{*}{$\begin{array}{c}\text { Total } \\
\text { Row \% }\end{array}$} & \multirow{3}{*}{$\mathrm{N}$} \\
\hline & & & & \\
\hline & Row \% & Row \% & & \\
\hline \multicolumn{5}{|l|}{ Age Group } \\
\hline $50-54$ & 47 & 53 & 100 & 1,461 \\
\hline $55-59$ & 47 & 53 & 100 & 1,436 \\
\hline $60-64$ & 47.1 & 52.9 & 100 & 1,192 \\
\hline Total & 47 & 53 & 100 & 4,089 \\
\hline \multicolumn{5}{|l|}{ Highest education achieved } \\
\hline Primary/none & 52.9 & 47.1 & 100 & 802 \\
\hline Secondary & 48.5 & 51.5 & 100 & 1,837 \\
\hline Third/higher & 41.9 & 58.1 & 100 & 1,450 \\
\hline Total & 47 & 53 & 100 & 4,089 \\
\hline \multicolumn{5}{|l|}{ Household Income } \\
\hline Less than $\mathrm{E} 10,000$ & 46.6 & 53.4 & 100 & 348 \\
\hline More than $\mathrm{E} 10,000$ but less than $\mathrm{E} 20,000$ & 46.2 & 53.8 & 100 & 632 \\
\hline More than $\mathrm{E} 20,000$ but less than $\mathrm{E} 40,000$ & 44 & 56 & 100 & 1,360 \\
\hline More than $E 40,000$ but less than $E 70,000$ & 50.1 & 49.9 & 100 & 1,155 \\
\hline More than E70,000 & 49 & 51 & 100 & 594 \\
\hline Total & 47 & 53 & 100 & 4,089 \\
\hline \multicolumn{5}{|l|}{ Marital Status } \\
\hline Married & 48.6 & 51.4 & 100 & 3,119 \\
\hline Never married & 55.9 & 44.1 & 100 & 392 \\
\hline Sep/divorced & 35.6 & 64.4 & 100 & 382 \\
\hline Widowed & 26.5 & 73.5 & 100 & 196 \\
\hline Total & 47 & 53 & 100 & 4,089 \\
\hline \multicolumn{5}{|l|}{ Has children } \\
\hline No children & 56.4 & 43.6 & 100 & 580 \\
\hline Has children & 45.5 & 54.5 & 100 & 3,509 \\
\hline Total & 47 & 53 & 100 & 4,089 \\
\hline \multicolumn{5}{|l|}{ Health: good } \\
\hline Not good health & 45.8 & 54.2 & 100 & 1,538 \\
\hline Good health & 47.7 & 52.3 & 100 & 2,551 \\
\hline Total & 47 & 53 & 100 & 4,089 \\
\hline \multicolumn{5}{|l|}{ Health: excellent } \\
\hline Not excellent health & 48.2 & 51.8 & 100 & 3,325 \\
\hline Excellent health & 41.9 & 58.1 & 100 & 764 \\
\hline Total & 47 & 53 & 100 & 4,089 \\
\hline \multicolumn{5}{|l|}{ Poor childhood } \\
\hline Childhood not poor & 45.1 & 54.9 & 100 & 3,263 \\
\hline Poor childhood & 54.5 & 45.5 & 100 & 826 \\
\hline Total & 47 & 53 & 100 & 4,089 \\
\hline \multicolumn{5}{|l|}{ Long-term Health Problem } \\
\hline Yes & 44.9 & 55.1 & 100 & 1,421 \\
\hline No & 48.2 & 51.8 & 100 & 2,666 \\
\hline Total & 47 & 53 & 100 & 4,087 \\
\hline \multicolumn{5}{|l|}{ Any (I)ADL Impairments } \\
\hline No(I)ADL Impairments & 47.1 & 52.9 & 100 & 3,783 \\
\hline Any(I)ADL Impairments & 46.1 & 53.9 & 100 & 306 \\
\hline Total & 47 & 53 & 100 & 4,089 \\
\hline \multicolumn{5}{|l|}{ Integrated } \\
\hline Not social integrated & 45.7 & 54.3 & 100 & 868 \\
\hline Socially integrated & 47.4 & 52.6 & 100 & 3,221 \\
\hline Total & 47 & 53 & 100 & 4,089 \\
\hline
\end{tabular}




\begin{tabular}{|c|c|c|c|}
\hline & $\begin{array}{c}\text { All } \\
\mathrm{b} / \mathrm{se}\end{array}$ & $\begin{array}{c}\text { Female } \\
\text { b/se }\end{array}$ & $\begin{array}{l}\text { Male } \\
\mathrm{b} / \mathrm{se}\end{array}$ \\
\hline \multirow[t]{2}{*}{ Male } & $-1.333 * * *$ & & \\
\hline & $(0.227)$ & & \\
\hline \multirow[t]{2}{*}{ Age } & $-0.188 * * *$ & $-0.176 * * *$ & $-0.185^{* * *}$ \\
\hline & (0.029) & $(0.041)$ & $(0.038)$ \\
\hline \multirow[t]{2}{*}{ Never married } & $1.278 * *$ & 0.077 & $2.105^{* * *}$ \\
\hline & $(0.578)$ & $(0.795)$ & $(0.801)$ \\
\hline \multirow[t]{2}{*}{ Separated/divorced } & $1.706 * * *$ & $1.510 * *$ & $1.798^{* *}$ \\
\hline & $(0.479)$ & $(0.623)$ & $(0.728)$ \\
\hline \multirow[t]{2}{*}{ Widowed } & $1.959 * * *$ & $1.755^{* * *}$ & $2.251 *$ \\
\hline & $(0.586)$ & $(0.647)$ & $(1.308)$ \\
\hline \multirow[t]{2}{*}{ Has children } & -0.330 & -0.272 & -0.315 \\
\hline & $(0.478)$ & $(0.650)$ & $(0.650)$ \\
\hline \multirow[t]{2}{*}{ Urban } & -0.444 & -0.357 & -0.524 \\
\hline & $(0.369)$ & $(0.522)$ & $(0.476)$ \\
\hline \multirow[t]{2}{*}{ Rural } & $-0.848 * * *$ & $-1.058^{* *}$ & $-0.723^{*}$ \\
\hline & $(0.320)$ & $(0.439)$ & $(0.428)$ \\
\hline \multirow[t]{2}{*}{ Secondary } & -0.465 & -0.696 & -0.167 \\
\hline & $(0.324)$ & $(0.519)$ & $(0.402)$ \\
\hline \multirow[t]{2}{*}{ Tertiary/Higher } & -0.104 & -0.671 & 0.583 \\
\hline & (0.349) & $(0.534)$ & $(0.438)$ \\
\hline \multirow[t]{2}{*}{$E 10,000-E 20,000$} & -1.010 & -1.347 & -0.526 \\
\hline & $(0.624)$ & $(0.836)$ & $(0.857)$ \\
\hline \multirow[t]{2}{*}{$E 20,000-E 40,000$} & $-1.473^{* * *}$ & $-1.458 * *$ & -1.166 \\
\hline & $(0.543)$ & (0.739) & $(0.755)$ \\
\hline \multirow[t]{2}{*}{$\mathrm{E} 40,000-\mathrm{E} 70,000$} & $-1.919 * * *$ & $-2.350 * * *$ & $-1.353^{*}$ \\
\hline & $(0.560)$ & $(0.771)$ & $(0.742)$ \\
\hline \multirow[t]{2}{*}{ More than E70,000 } & $-2.493^{* * *}$ & $-2.616^{* * *}$ & $-2.177 * * *$ \\
\hline & $(0.592)$ & $(0.816)$ & $(0.806)$ \\
\hline \multirow[t]{2}{*}{ Health: good } & $-3.069 * * *$ & $-3.873 * * *$ & $-2.412 * * *$ \\
\hline & $(0.387)$ & $(0.561)$ & $(0.544)$ \\
\hline \multirow[t]{2}{*}{ Health: excellent } & $-4.529 * * *$ & $-5.317 * * *$ & $-3.776 * * *$ \\
\hline & $(0.414)$ & $(0.598)$ & $(0.577)$ \\
\hline \multirow[t]{2}{*}{ Poor childhood } & $0.808^{* * *}$ & $1.239 * * *$ & 0.518 \\
\hline & $(0.289)$ & $(0.434)$ & $(0.376)$ \\
\hline \multirow[t]{2}{*}{ Doctor diagnosed disease } & 0.281 & -0.041 & $0.597^{*}$ \\
\hline & $(0.249)$ & $(0.345)$ & $(0.361)$ \\
\hline \multirow[t]{2}{*}{ Any (I)ADL Impairments } & $5.015 * * *$ & $5.534 * * *$ & $4.527^{* * *}$ \\
\hline & $(0.640)$ & $(0.957)$ & $(0.873)$ \\
\hline \multirow[t]{2}{*}{ Integrated } & $-1.145^{* * *}$ & $-1.377 * * *$ & $-0.851 * *$ \\
\hline & $(0.309)$ & $(0.458)$ & $(0.392)$ \\
\hline \multirow[t]{2}{*}{ Not employed } & $1.349 * * *$ & $1.022^{* * *}$ & $1.574 * * *$ \\
\hline & $(0.259)$ & $(0.341)$ & $(0.375)$ \\
\hline Observations & 4089 & 2166 & 1923 \\
\hline $\mathrm{R}^{2}$ & 0.190 & 0.205 & 0.168 \\
\hline
\end{tabular}

Notes: Standard errors in parentheses 
Table 4 OLS: Does the Association between Employment Norms depend on Employment Status?

\begin{tabular}{|c|c|c|c|}
\hline & (1) & (2) & (3) \\
\hline & All & Female & Male \\
\hline & $\mathrm{b} / \mathrm{se}$ & $\mathrm{b} / \mathrm{se}$ & $\mathrm{b} / \mathrm{se}$ \\
\hline \multirow[t]{2}{*}{ Male } & $-1.216^{\star \star \star}$ & & \\
\hline & $(0.274)$ & & \\
\hline \multirow[t]{2}{*}{ Not employed } & $3.126^{\star \star \star}$ & $3.498^{\star \star \star}$ & $3.435^{\star \star \star}$ \\
\hline & $(0.720)$ & (1.279) & (0.963) \\
\hline \multirow[t]{2}{*}{ Prop. NE(CGA) } & $2.244^{\star \star}$ & 1.779 & $4.006^{\star \star \star}$ \\
\hline & $(1.124)$ & $(1.838)$ & $(1.352)$ \\
\hline \multirow[t]{2}{*}{ NE*Prop. NE(CGA) } & $-4.043^{\star * \star}$ & $-4.920^{*}$ & -4.920 *** \\
\hline & $(1.427)$ & $(2.207)$ & $(2.207)$ \\
\hline Controls & Yes & Yes & Yes \\
\hline Observations & 4089 & 2166 & 1923 \\
\hline$R^{2}$ & 0.192 & 0.207 & 0.172 \\
\hline
\end{tabular}

${ }^{*} p<0: 10,{ }^{* *} p<0: 05,{ }^{* * *} p<0: 01$

Notes: Standard errors in parentheses

Table 5 Ordered Probit: Does the Association between Employment Norms depend on Employment Status?

\begin{tabular}{lccc}
\hline \hline & $(1)$ & $(2)$ & $(3)$ \\
& $\begin{array}{c}\text { All } \\
\text { b/se }\end{array}$ & $\begin{array}{c}\text { Female } \\
\text { b/se }\end{array}$ & $\begin{array}{c}\text { Male } \\
\text { b/se }\end{array}$ \\
\hline Male & $-0.243^{\star \star *}$ & & \\
& $(0.053)$ & & \\
Not employed & $0.386^{\star \star *}$ & $0.365^{\star \star}$ & $0.412^{\star \star *}$ \\
& $(0.123)$ & $(0.209)$ & $(0.163)$ \\
Prop. NE & $0.517^{\star *}$ & 0.244 & $0.889^{\star * *}$ \\
& $(0.245)$ & $(0.340)$ & $(0.347)$ \\
NE*Prop. NE(CGA) & $-0.484^{\star *}$ & -0.505 & $-0.495^{*}$ \\
& $(0.260)$ & $(0.4009)$ & $(0.417)$ \\
Controls & & & \\
\hline Observations & Yes & Yes & Yes \\
\hline R2 & 4089 & 2166 & 1923 \\
\hline
\end{tabular}

${ }^{\star} p<0: 10,{ }^{* *} p<0: 05,{ }^{* * \star} p<0: 01$

Notes: Standard errors in parentheses. 